\title{
Non-Fourier effects in the thermal protection against high-power ultra-fast laser pulses
}

\author{
Marcin Lenarczyk ${ }^{1, *}$, and Roman Domański ${ }^{1}$ \\ ${ }^{1}$ Institute of Aviation, al. Krakowska 110/114, 02-256 Warsaw, Poland
}

\begin{abstract}
In this paper the heat transfer process between laser beam and a solid body is investigated in the context of the protective materials, which can be used in the military, manufacturing or scientific fields. An ultra-fast high-power interaction regime is being considered. Non-Fourier effects are taken into account. To simulate effects, which can be of significance in the protective materials design, Cattaneo-Vernotte equation is being solved by means of MacCormack explicit second order numerical scheme. Selected results are discussed in detail.
\end{abstract}

\section{Introduction}

The rapid development in the laser technology requires an adequate description of the heat transfer processes that are associated with the laser-solid interactions. In the recent years a special attention has been given to the ultra-short laser pulses that are applied in the fields such as laser weapons, manufacturing or confinement fusion research $[1,10,13]$.

A proper modelling of the ultra-fast interactions is crucial for obtaining reliable temperature fields in the considered problems $[3,5]$. The parameters of the lasers available commercially, used in the military or scientific fields such as pulse duration time and energy determine heat propagation regime which needs to be considered $[4,8,9]$. In the current paper non-Fourier heat propagation conditions are being considered. The investigation of the effects typical for the wave-like heat propagation and their influence on the temperature distribution in the given system are being studied.

\section{Page layout}

The classical heat conduction theory based on the Fourier's law assumes that thermal disturbance propagates with an infinite speed. For the most heat transfer problems this assumption is valid. However, when one considers ultra-fast processes of electromagnetic wave and solid interaction thermal propagation speed, as postulated by Cattaneo [2] and Vernotte [12], becomes relevant.

Transient one-dimensional heat conduction equation can be written as follows:

$$
\frac{\partial T(x, t)}{\partial t}=\alpha \frac{\partial^{2} T(x, t)}{\partial x^{2}}
$$

Eq. (1) is the classic Fourier equation and it assumes the infinite speed of heat propagation. In fact, as the heat conduction is accomplished by successive collisions of the energy carriers (phonons or electrons), the propagation of the thermal disturbance is always at the finite speed.

The paradox of the infinite thermal disturbance propagation speed was addressed by Cattaneo and Vernotte by introducing the thermal relaxation time parameter:

$$
\frac{\partial T(x, t)}{\partial t}+\tau_{R} \frac{\partial^{2} T(x, t)}{\partial t^{2}}=\alpha \frac{\partial^{2} T(x, t)}{\partial x^{2}}
$$

The comparison of temperature distributions obtained by using both equations can be seen in Figure 1 .

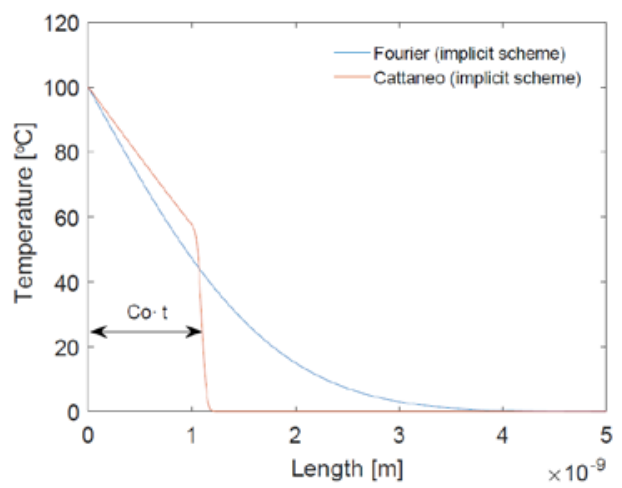

Fig. 1. Comparison of the temperature distributions obtained by solving Fourier and $\mathrm{C}-\mathrm{V}$ equations.

Eq. (2) is a hyperbolic partial differential equation in mathematical sense. Solution of the $\mathrm{C}-\mathrm{V}$ equation results in the temperature field disturbance (caused by i.e. subjecting the surface to the heat flux boundary condition) only in the distance of $C_{0} \cdot t$ from the surface. 
Irradiation of the thin film with thickness considerably smaller than the length allows to employ 1D approach in the $\mathrm{x}$-direction (across the thickness). Assuming that the side walls are suddenly subjected to the heat flux density, we can formulate the boundary conditions as follows:

$$
\begin{aligned}
& -\left.\frac{\partial T(x, t)}{\partial x}\right|_{x=0}=q_{W_{0}}(t) \\
& -\left.\frac{\partial T(x, t)}{\partial x}\right|_{x=L}=q_{W_{L}}(t)
\end{aligned}
$$

The initial conditions can be written as:

$$
\begin{gathered}
\left.T(x, t)\right|_{t=0}=T_{0}(x) \\
\left.\frac{\partial T(x, t)}{\partial t}\right|_{t=0}=T_{\text {init }}(x)
\end{gathered}
$$

The above mathematical model is used to compare solutions of the classical heat conduction and Cattaneo-Vernotte equations. The comparative analysis is performed to define potentially dangerous effects that might occur in the ultra-fast laser beam and solid interaction regime.

\section{Computational method}

MacCormack proposed second-order accurate explicit scheme to solve compressible Navier-Stokes equation [11]. As reported by [6] this scheme proved to handle well moving discontinuities, such as heat waves, and it is valid for hyperbolic heat conduction problems.

MacCormack discretization procedure is a two-step predictor corrector scheme which is based on nondimensional formulation. The non-Fourier heat flux equation can be written in the following form:

$$
q(x, t)+\tau_{R} \frac{\partial q(x, t)}{\partial t}=-\lambda \frac{\partial T(x, t)}{\partial x}
$$

The energy equation is given by:

$$
-\frac{\partial q(x, t)}{\partial x}=\rho c \frac{\partial T(x, t)}{\partial t}
$$

The dimensionless temperature, dimensionless heat flux, dimensionless time and space variables are defined as follows:

$$
\begin{gathered}
\theta(\eta, \zeta)=\frac{T-T_{0}}{\alpha q / \lambda c} \\
Q(\eta, \zeta)=\frac{T(x, t)-T_{0}}{\alpha q / k c} \\
\zeta=\frac{C_{0}^{2} t}{2 \alpha} \\
\eta=\frac{C_{0} x}{2 \alpha}
\end{gathered}
$$

Based on the MacCormack second-order accurate explicit scheme predictor and corrector expression can defined as:

$$
\begin{gathered}
\tilde{E}_{i}^{f+1}=E_{i}^{f}-\frac{\Delta \zeta}{\Delta \eta}\left[F_{i+1}^{f}-F_{i}^{f}\right]-\Delta \zeta H_{i}^{f} \\
E_{i}^{f+1}=\frac{1}{2}\left[E_{i}^{f}+\tilde{E}_{i}^{f+1}-\frac{\Delta \zeta}{\Delta \eta}\left(\tilde{F}_{i}^{f+1}-\tilde{F}_{i-1}^{n+1}\right)-\Delta \zeta \tilde{H}_{i}^{n+1}\right]
\end{gathered}
$$

Where:

$$
E=\left[\begin{array}{l}
\theta(\eta, \zeta) \\
Q(\eta, \zeta)
\end{array}\right] F=\left[\begin{array}{l}
Q(\eta, \zeta) \\
\theta(\eta, \zeta)
\end{array}\right] H=\left[\begin{array}{c}
0 \\
2 Q(\eta, \zeta)
\end{array}\right]
$$

The stability criterion for this method, when applied to a linear equation, is $v \leq 1$, where $v=\Delta \zeta / \Delta \eta$ is the Courant number. However, due to nonlinear nature of the present equations, the stability criterion is reduced. As the Courant number becomes smaller, the effect of odd derivative truncation error terms becomes larger, and oscillations occur in the vicinity of discontinuities in the solution [7].

\section{Simulation results}

Throughout the numerical simulations that were performed within the scope of the study, the numbers of results have been obtained. The following section presents selected cases.

Figure 2 presents the overview of the temperature evolution in the considered system. Duration time and heat flux density magnitude have been set up arbitrary to illustrate effects, which could be potentially dangerous for the laser protection system.

After the boundary conditions on both sides are imposed, a set of wave fronts is being created in the domain. Thermal wave propagation starts to advance toward centre.

The propagation front separates the thermally affected zone from the thermally undistributed region. Once wave fronts arrive at the centre of the film, they collide with each other causing a sudden and significant temperature increase in this region.

Consequently, revers thermal wave fronts emerge, and they begin to advance toward side walls. Once reverse waves reach the boundary region, the temperature at both walls exceeds the initial wall temperature (as an effect of wave reflection) creating temperature overshoot.

Performed numerical study predicts the existence of thermal waves providing both the amplification and shape. In the investigated case, the sudden temperature increase due to waves collision in the centre of the structure occurs at $4.55 \cdot 10^{-15} \mathrm{~s}$. The side walls temperature at the time step equals to $470{ }^{\circ} \mathrm{C}$. The maximum peak temperature in the system equals to $599^{\circ} \mathrm{C}$, rising suddenly from $284^{\circ} \mathrm{C}$. It means that the system experienced step temperature jump by $210 \%$ with respect to the before-the-collision temperature in the centre of the structure. While considering the side wall as a reference, the peak temperature raised by $27 \%$. 
As the reverse waves reach the side walls, the temperature overshoot effect occurs at $9.1 \cdot 10^{-15} \mathrm{~s}$. Both side walls temperature suddenly rises from $555^{\circ} \mathrm{C}$ to $986^{\circ} \mathrm{C}$, which corresponds to $77 \%$ increase.

A similar reflection effect can be observed once one of the wall is well insulated. Let assume identical conditions as for the above described case, with exception for the right wall boundary condition, which for the current case is subjected to the heat flux density $q_{W} L=0 \mathrm{~W} / \mathrm{m}^{2}$.

Figure 3 illustrates temperature distribution in the system in the consecutive time steps.
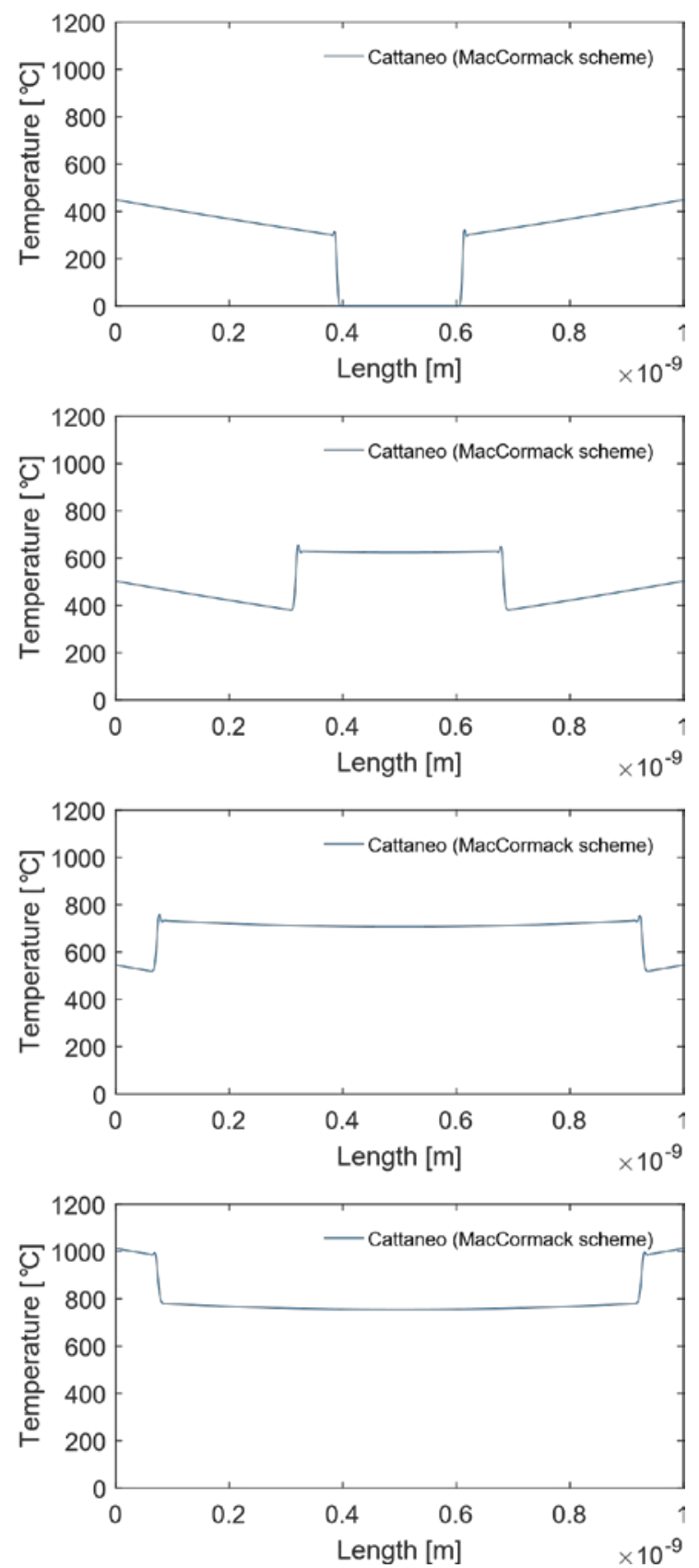

Fig. 2. Heat waves collision. Neumann BC. Temperature distribution. Results for time steps: $3.5 \cdot 10^{-15} \mathrm{~s}, 6.2 \cdot 10^{-15} \mathrm{~s}$, $8.4 \cdot 10^{-15} \mathrm{~s}$ and $9.7 \cdot 10^{-15} \mathrm{~s}$. Heat flux density $\mathrm{q}=1 \cdot 10^{14} \mathrm{~W} / \mathrm{m}^{2}$ on the both side walls assumed as a boundary condition.
The wave front is being created after the boundary condition is imposed on the left wall. Thermal wave propagates toward insulated wall. Once the front collides with the wall, the sudden temperature increase occurs, and the reverse thermal front emerges. New front advances toward the left wall and after the second collision it causes the temperature overshot.
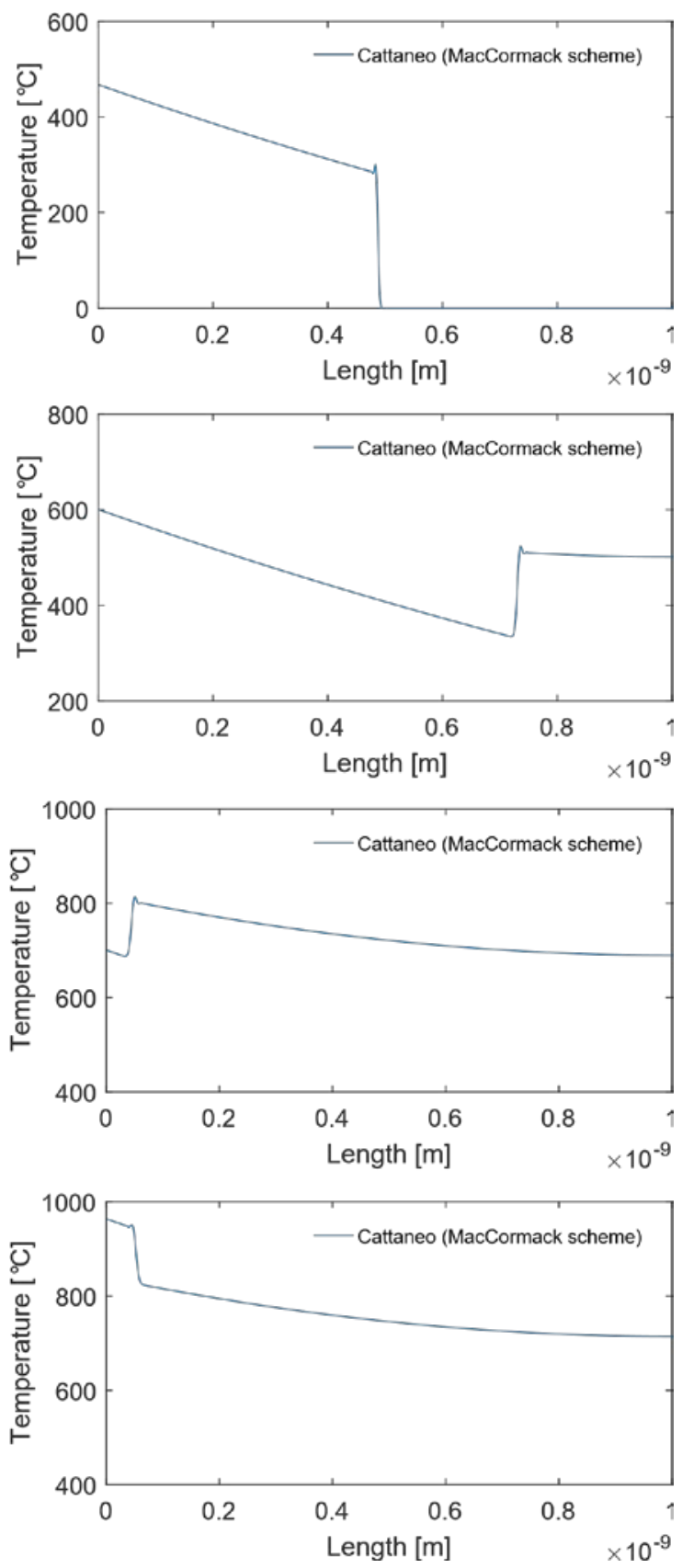

Fig. 3. Heat wave reflection from the insulated wall. Neumann BC. Results for time steps: $4.5 \cdot 10^{-15} \mathrm{~s}, 1.1 \cdot 10^{-14} \mathrm{~s}, 1.7 \cdot 10^{-14} \mathrm{~s}$ and $1.8 \cdot 10^{-14} \mathrm{~s}$. Heat flux density $\mathrm{q}_{\mathrm{L}}=1 \cdot 10^{14} \mathrm{~W} / \mathrm{m}^{2}$ on the left side wall and $\mathrm{q}_{\mathrm{R}}=0 \mathrm{~W} / \mathrm{m}^{2}$ assumed as the boundary conditions.

The numerical analysis of the configuration consisting of two materials with various relaxation times has been carried out. Obtained results suggest that a discontinuity such a transition from one material to the other can result in a reverse wave creation. A wave 
which emerged at the materials boundary is traveling in the backward direction advancing towards wall subjected to the Neumann boundary condition.

In Figure 4 one can see the results showing temperature distribution in the dimensionless domain for two materials, where $\tau_{R 1}=1 \cdot 10^{-11} \mathrm{~s}$ and $\tau_{R 2}=1 \cdot 10^{-13} \mathrm{~s}$. Assuming that density, specific heat capacity and thermal conductivity are the same for both materials, speed of wave front is $C_{01}=1 \cdot 10^{3} \mathrm{~m} / \mathrm{s}$ and $C_{02}=1 \cdot 10^{4}$ $\mathrm{m} / \mathrm{s}$, respectively, for the right and left sides.

This result should be treated as a potential effect that needs further investigation and it is beyond the scope of the present study. The author has not found any confirmation of such a phenomenon in the experimental data available in the literature. However, if this kind of effect existed in nature, then it should be qualified as another thermal response that might be of significance while evaluating thermal performance of the system.

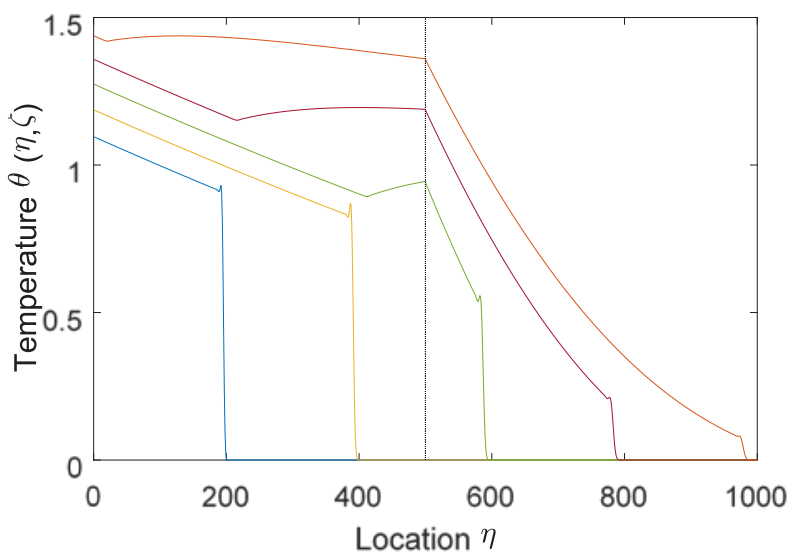

Fig. 4. Wave reflection at the two materials' interface.

For all the presented numerical calculations the energy balance check was done. The balance was carried out by comparing heat accumulated by the system versus heat delivered to the system. The accumulated heat is determined based on temperature distribution at a given time step.

$$
\begin{gathered}
Q_{A C C}=m c_{p} T(x, t) \\
Q_{A C C}=A \rho c_{p} \int_{0}^{L} T(x, t) d x
\end{gathered}
$$

Heat delivered to the system is calculated by means of the control surface at the side walls and heat flux integration over time

$$
Q_{D E L}=A \int_{0}^{T} q(t) d t
$$

Figure 5 presents the energy balance of the wavewall interaction scenario. For the comparison purposes, value of the area, A, is set up to 1 . It is seen that the heat accumulated by the system, $\mathrm{Q}_{\mathrm{ACC}}$, is equal to heat deliver to the system, $\mathrm{Q}_{\mathrm{DEL}}$, over time.

\section{Summary and conclusions}

In the presented study the MacCormack numerical algorithm has been adopted to solve the hyperbolic heat conduction equation. A comparative analysis of the solution of the classical heat conduction equation and the Cattaneo-Vernotte equation is performed for the Neumann boundary conditions.

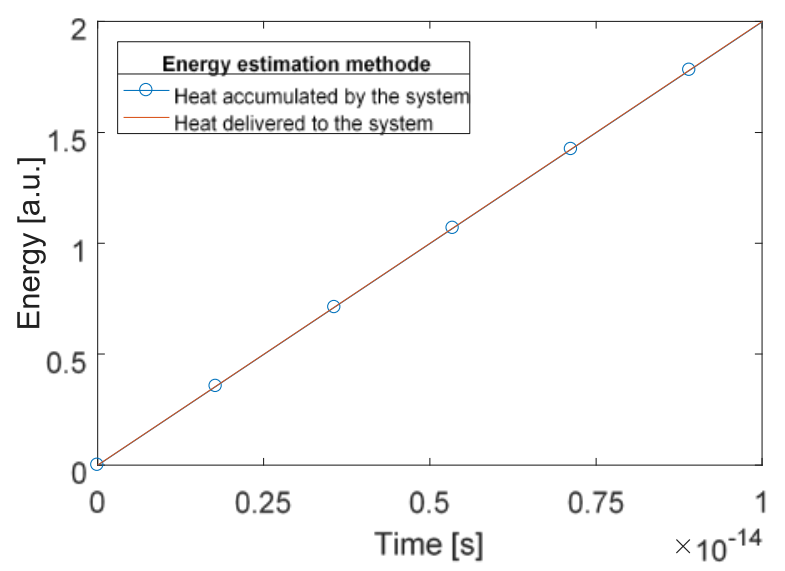

Fig. 5. Energy balance check. Comparison of heat accumulated by the system with heat delivered to the system over time.

The investigation of the heat waves collision phenomenon is carried out. Two effects have been identified as potentially relevant for the thermal barriers which are meant to interact with the laser radiation. The first effect occurs after waves' collision. It results in a step change of the temperature inside the structure, which can lead to the limit exceedance. The second effect is the temperature overshoot on the side wall, which is the result of the backward wave and the wall interaction.

In the example that illustrates the phenomenon, the maximum temperature overshot was equal to twice the temperature in the centre of the structure before the collision. This suggests that the described effect might be potentially dangerous for the considered system.

Laser-matter interaction and the associated heat transfer process are very complex phenomena. Both are still subjects of extensive research efforts. Prediction of the temperature field in the irradiated solid requires not only comprehensive heat transfer model, but also reliable material properties.

The dynamic of the process and lack of detailed material data (in particular the relaxation time parameter) are, among others, the reasons why till now there is no versatile correlation that would allow for precise prediction of the temperature evolution in such a system.

It is also crucial to point out that all the considerations on the particular protective system should be done in the context of the laser wavelength, which determines the absorption mechanism. If one knows the wavelength of the radiation source, then the set-up of the dedicated material configuration can be chosen accordingly. A separate effort should be undertaken in 
order to build a relation between radiation wavelength and corresponding hardware protection strategy.

\section{Nomenclature}

$C_{0} \quad-$ speed of the thermal wave, $\mathrm{m} / \mathrm{s}$,

c - specific heat, $\mathrm{J} /(\mathrm{kg} \cdot \mathrm{K})$

$L \quad$ - length of the system, m,

$Q \quad$ - dimensionless heat flux, -,

$q-$ heat flux, $\mathrm{W} / \mathrm{m}^{2}$,

$T$ - temperature, ${ }^{\circ} \mathrm{C}$,

$t$ - time, s,

$x \quad$ - spatial variable, $\mathrm{m}$,

\section{Greek symbols}

$\alpha \quad-$ thermal diffusivity, $\mathrm{m}^{2} / \mathrm{s}$,

$\zeta \quad$-dimensionless time variable, - ,

$\eta \quad$ - dimensionless space variable, - ,

$\theta \quad$ - dimensionless temperature, - ,

$\lambda$ - thermal conductivity, $\mathrm{W} /(\mathrm{m} \cdot \mathrm{K})$,

$v \quad-$ Courant number, - ,

$\rho-$ mass density, $\mathrm{kg} / \mathrm{m}^{3}$,

$\tau_{R} \quad$ - relaxation time, $\mathrm{s}$.

\section{References}

1. M.S. Brown, C.B. Arnold, Fundamentals of LaserMaterial Interaction and Application to Multiscale Surface Modification, in: Laser Precis. Microfabr., Springer-Verlag Berlin Heidelberg, 2010: pp. 91120.

2. C. Cattaneo, Sur une Forme de I'equation de la Chaleur Eliminant le Paradoxe d'une Propagation Instantanee', Comptes Rendus l'Académie Des Sci. 247 (1958) 431-433.
3. R. Domański, Badanie przewodzenia ciepła w ciałach stałych przy impulsowo działającym strumieniu ciepła, Dr. Thesis Inst. Heat Eng. Warsaw Univ. Technol. (1976).

4. R. Domański, Badanie cieplnych efektów działania gigantycznego impulsu laserowego na powierzchnie nieprzezroczystych ciał stałych, Arch. Termodyn. 2 (1981).

5. R. Domański, Promieniowanie laserowe oddziaływanie na ciała stałe, Wydawnictwa Naukowo-Techniczne, Warsaw, 1990.

6. D.E. Glass, M.N. Özişik, D.S. McRae, B. Vick, On the numerical solution of hyperbolic heat conduction, Numer. Heat Transf. 8 (1985) 497-504.

7. D.E. Glass, M.N. Özişik, D.S. McRae, B. Vick, Hyperbolic heat conduction with temperaturedependent thermal conductivity, J. Appl. Phys. 59 (1986) 1861-1865.

8. M. Lenarczyk, Hardware protection against laser impulses using materials with a complex structure, PhD Thesis Inst. Aviat. Warsaw. (2018).

9. M. Lenarczyk, R. Domański, Investigation of nonFourier thermal waves interaction in a solid material, Arch. Thermodyn. Accepted (2018).

10. M.C. Levy, T.G. Blackburn, N. Ratan, J. Sadler, C.P. Ridgers, M. Kasim, L. Ceurvorst, J. Holloway, M.G. Baring, A.R. Bell, S.H. Glenzer, G. Gregori, A. Ilderton, M. Marklund, M. Tabak, S.C. Wilks, P.A. Norreys, QED-driven laser absorption, Plasma Physics, Cornell Univ. Libr. 1 (2016) 1-10.

11. R. MacCormack, The effect of viscosity in hypervelocity impact cratering, in: 4th Aerodyn. Test. Conf., American Institute of Aeronautics and Astronautics, 1969.

12. P. Vernotte, La véritable équation de la chaleur, Compt. Rend. Acad. Sci. 247 (1958) 2103-2105.

13. L.D. Welch, D.C. Latham, Report of the Defense Science Board Task Force on High Energy Laser Weapon Systems Application, 2001. 